\title{
The features of Saaty analytic hierarchy process application for the choice of modernization strategy of energy objects
}

\author{
Natalia Fedorova, ${ }^{1, *}$ \\ ${ }^{1}$ Platov South-Russian State Polytechnic University (NPI), Prosveshcheniya str. 132, Novocherkassk, Russia
}

\begin{abstract}
The article is devoted to identifying the features of application the Analytic Hierarchy Process (AHP) when choosing the modernization strategies to thermal power plant (TPP) subsystems and convert TPP into an energy technological complex (ETC). Criteria for evaluating the effectiveness of alternative energy projects are presented. It is shown that the use of optimization methods makes it possible to reduce the influence of the subjectivity of the decision maker (DM) at the upper levels of the hierarchy. The method of parallel hierarchies is proposed, which allows in one model to take into account the influence of nonsubordinate tasks and problems of energy production.
\end{abstract}

\section{Introduction}

Currently, there are a number of problems at thermal energy facilities in Russia, such as thermal power plants, centralized heat supply boilers: the moral and physical deterioration of equipment, the need to use the coal of degraded quality, the accumulation of ash and slag waste, increasing demands on the composition and temperature of flue gases. These problems need to be addressed when modernizing existing thermal power plants and designing new ones. At the same time, projects of equipment and technologies with higher efficiency have been developed in Russia and other countries of the world, allowing the separation and utilization of ash and slag materials (ASM), taking into account their physical and chemical properties, which allow cooling downstream gases dispose of acid oxides contained in them. The problem arises of a multicriteria choice of the optimal strategy for the modernization of an energy facility. At the same time, projects of equipment and technologies with higher efficiency have been developed in Russia and other countries of the world, allowing the separation and utilization of ash and slag materials (ASM), taking into account their physical and chemical properties, which allow cooling downstream gases dispose of acid oxides contained in them. The problem arises of a multi-criteria choice of the optimal strategy for the modernization of an energy facility.

To solve the problems of choosing a strategy from a number of alternative variants, the American mathematician T. Saaty developed a method for analyzing hierarchies (Analytic Hierarchy Process - AHP) [1, 2], since the 70 s of the 20th century it has been successfully used in various spheres of human activity [3-9], including in the energy sector [10-12]. This article presents the results of the author's research on the choice of strategies for coal-fired TPP subsystems modernization (fuel preparation, oxidizer preparation, separation and recycling of ash-and-slag materials, utilization of flue gas heat and components) and modernization of thermal power plants as a whole using the AHP, features of the AHP application to the choice of modernization strategy for the industrial energy facilities identified and analyzed.

\section{The method of AHP application}

The method of AHP application consists in the sequential implementation of the stages: building a model of the problem in the form of a hierarchy, including the goal, alternative projects for achieving the goal and criteria for alternatives evaluating; determination of local priorities of all members of the hierarchy in relation to the criteria of the next higher level; synthesis of global priorities of alternatives by linear convolution of the priorities of elements on the hierarchy; verification of judgments on consistency, error estimation, probability of error; decision making based on the results.

When choosing an energy facility modernization strategy:

- the goal is to increase the efficiency of its work;

- alternative projects that allow to achieve the set goal are selected from the options available for implementation (technologies and special equipment on the market) or innovative (currently at the stage of research and development or experimental development);

- performance criteria take into account the peculiarities of the TPP as an economic and technical object.

Taking into account modern economic relations, the priority of criteria (groups of criteria) in descending order was considered, as a rule, in sequence: economic $\rightarrow$ technical $\rightarrow$ ecological $\rightarrow$ others. Among others criteria, legal (legislative support for technological solutions), organizational (presence of specialized organizations, for example, for utilization of ASM), social 
(creation of new jobs, requirements for staff qualifications), infrastructure, risk can be separately identified.

When evaluating alternative projects from the perspective of one or another criterion, as a rule, the priority of projects was built quite clearly. Most of the criteria allow for a numerical assessment (equipment is more expensive/cheaper, efficiency is higher/lower, the project provides for the creation of more/fewer jobs) or obvious qualitative assessment (the region's environment improves/does not deteriorate/deteriorates significantly, specialized organizations for project implementation is present/absent in the region, risks of different nature in the project implementation are high/low/not assessed).

When assessing the priority of criteria (especially groups of criteria) from the standpoint of achieving the goal, solving the problem, the situation is not so obvious and unambiguous. At this level, the subjective preferences of the decision-maker (DM), the socio-political conjuncture, begin to play a big role. This subjectivity undermines the credibility to the results of modeling, creates the illusion that by manipulating «with numbers» any project can become a leader.

The consistency of the pairwise comparisons matrix was evaluated by the value of the consistency relationship (CR) [2], the value of CR $\leq 0.10$ is considered acceptable. The consistency of the global alternatives priorities vector and the error of the calculations were determined by constructing the geometric mean normalized vector of global priorities and estimating the deviation of the averaged priorities from the primary ones, a deviation of no more than $10 \%$ is considered acceptable. Saaty also stipulates the feasibility of taking Miller's hypothesis into account: evaluate no more than $7+2$ components at each level.

Consider the models of the choice of TPP subsystems modernization projects.

\section{Modernization of the fuel preparation system at the coal power plant}

Alternative projects were considered: $\mathrm{CE}$ - modernization of the traditional fuel preparation system with the introduction of the coal preparation site by enrichment, reducing the ash content of coal to $6-10 \%$ by weight; AC - modernization of the traditional fuel preparation system with the introduction of the fuel preparation site by introducing additives to activate / catalyze combustion; TR - «zero» or the traditional version, updating the equipment for fuel preparation without changing the technological scheme; criteria: EN - economic; TT - technical and technological; EL - ecological; R - risky. The problem model is presented in fig. 1 , the results of the calculations - in the table 1 and 2.

According to the table 1 , in the short term, traditional modernization has the highest priority, as it requires less investment. According to the table 2, in the long term, the modernization strategy with the introduction of a coal preparation plant has the highest priority, since the costs of maintenance, repair and replacement of equipment, environmental payments, and ultimately the cost of energy produced at TPPs are reduced. Calculation error does not exceed $5 \%$.

Goal
Criteria
$\begin{aligned} & \text { Alternative } \\ & \text { projects }\end{aligned}$

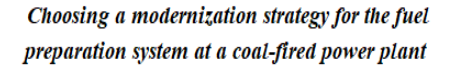

preparation system at a coal-fired power plant

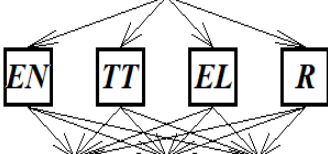

CE $A C \quad T R$
Fig. 1. Model of the problem of choosing the modernization strategy for the fuel preparation system at a coal power plant.

Table 1. Calculation results when choosing a strategy for modernization the system for preparing fuel at a coal-fired power plant, short-term perspective.

\begin{tabular}{|c|c|c|c|c|c|c|c|c|c|}
\hline \multirow{6}{*}{$\begin{array}{c}\text { Alternative } \\
\text { projects }\end{array}$} & \multicolumn{6}{|c|}{ Criteria } & \multirow{4}{*}{\multicolumn{3}{|c|}{$\begin{array}{c}\text { Global priorities } \\
\text { for alternative } \\
\text { projects }\end{array}$}} \\
\hline & & & EN & TT & EL & $\mathrm{R}$ & & & \\
\hline & \multicolumn{6}{|c|}{$\begin{array}{l}\text { The numerical value of the } \\
\text { priority vector }\end{array}$} & & & \\
\hline & \multirow{3}{*}{$\begin{array}{l}\text { Dive } \\
\text { rsity }\end{array}$} & 1 & 0.45 & 0.29 & 0.17 & 0.09 & & & \\
\hline & & 2 & 0.45 & 0.17 & 0.29 & 0.09 & \multicolumn{3}{|c|}{ Diversity } \\
\hline & & 3 & 0.45 & 0.09 & 0.17 & 0.29 & 1 & 2 & 3 \\
\hline $\mathrm{CE}$ & & & 0.23 & 0.31 & 0.53 & 0.53 & 0.33 & 0.36 & 0.37 \\
\hline $\mathrm{AC}$ & & & 0.26 & 0.16 & 0.31 & 0.16 & 0.23 & 0.25 & 0.23 \\
\hline TR & & & 0.52 & 0.53 & 0.16 & 0.31 & 0.44 & 0.40 & 0.40 \\
\hline
\end{tabular}

Table 2. Calculation results when choosing a strategy for modernization the system for preparing fuel at a coal-fired power plant, long-term perspective.

\begin{tabular}{|c|c|c|c|c|c|c|c|c|c|}
\hline \multirow{6}{*}{$\begin{array}{c}\text { Alternative } \\
\text { projects }\end{array}$} & \multicolumn{6}{|c|}{ Criteria } & \multirow{4}{*}{\multicolumn{3}{|c|}{$\begin{array}{c}\text { Global priorities } \\
\text { for alternative } \\
\text { projects }\end{array}$}} \\
\hline & & & EN & TT & EL & $\mathrm{R}$ & & & \\
\hline & \multicolumn{6}{|c|}{$\begin{array}{l}\text { The numerical value of the } \\
\text { priority vector }\end{array}$} & & & \\
\hline & \multirow{3}{*}{$\begin{array}{l}\text { Dive } \\
\text { rsity }\end{array}$} & 1 & 0.45 & 0.29 & 0.17 & 0.09 & & & \\
\hline & & 2 & 0.45 & 0.17 & 0.29 & 0.09 & \multicolumn{3}{|c|}{ Diversity } \\
\hline & & 3 & 0.45 & 0.09 & 0.17 & 0.29 & 1 & 2 & 3 \\
\hline $\mathrm{CE}$ & & & 0.53 & 0.31 & 0.53 & 0.53 & 0.47 & 0.50 & 0.51 \\
\hline $\mathrm{AC}$ & & & 0.31 & 0.16 & 0.31 & 0.16 & 0.25 & 0.27 & 0.25 \\
\hline TR & & & 0.16 & 0.53 & 0.16 & 0.31 & 0.28 & 0.24 & 0.24 \\
\hline
\end{tabular}

\section{Modernization of the oxidizer preparation system at TPPs}

Alternative projects: A50 - air enrichment to $50 \%$ oxygen, without $\mathrm{CO} 2$ utilization; A99 - enrichment of air to the content of $99 \%$ oxygen, with subsequent utilization of $\mathrm{CO}$; A21 - «zero» variant, lack of enrichment of air and utilization of $\mathrm{CO} 2$, renewal of the equipment of the air preparation system (APS) without changing the technological scheme. Factors (groups of criteria): EN economic; TT - technical and technological; EL ecological; R - risks. Criteria: CEP - the cost of electricity production; NI - necessary investments in capital and current expenses; PBP - payback period of the modernization project; DBP - demand and competitiveness of by-products; PUT - the possibility of using by-products directly at TPPs; CP - coefficient of performance, the efficiency of the equipment and the 


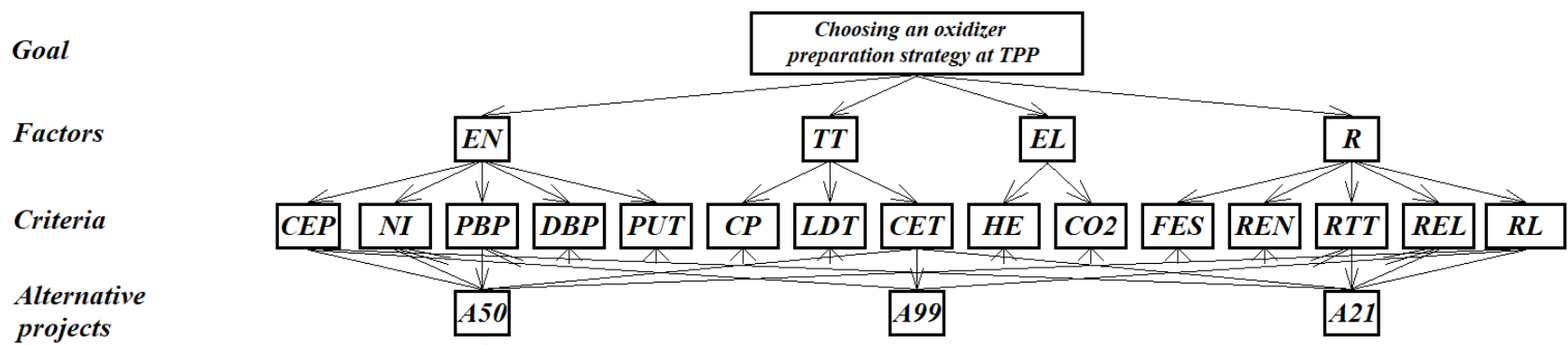

Fig. 2. Model of the problem of choosing the strategy of oxidizer preparation at TPPs.

technological cycle as a whole; LDT - the level of development and availability of appropriate technologies for alternative project; CET - complexity of equipment and technology; $\mathrm{HE}$ - the level of harmful emissions from the introduction of technology; $\mathrm{CO} 2$ - perspectives of $\mathrm{CO} 2$ utilization as a result of technology implementation; FES - fire and explosion safety; REN - economic risks; RTT technical and technological risks; REL - environmental risks; RL - legal risks. The problem model is presented in fig. 2 , the results of the calculations - in the table 3 .

Table 3. Evaluation of global priorities for alternative projects, APS.

\begin{tabular}{|c|c|c|c|c|c|}
\hline \multirow{2}{*}{$\begin{array}{c}\text { Alternative } \\
\text { projects }\end{array}$} & \multicolumn{4}{|c|}{ Factors and priorities } & \multirow{2}{*}{$\begin{array}{c}\text { Final } \\
\text { grade }\end{array}$} \\
\cline { 2 - 5 } & 0.45 & 0.29 & 0.17 & 0.09 & \\
\hline A50 & 0.48 & 0.41 & 0.27 & 0.49 & 0.42 \\
\hline A99 & 0.13 & 0.18 & 0.59 & 0.12 & 0.23 \\
\hline A21 & 0.39 & 0.41 & 0.14 & 0.39 & 0.35 \\
\hline $\begin{array}{c}\text { Amount by } \\
\text { column }\end{array}$ & 1 & 1 & 1 & 1 & 1 \\
\hline
\end{tabular}

The global priority of the alternative project A50 (Table 3) is the highest, this project is the leader in terms of economic and risk factors, followed by the alternative A21 («zero option») with high priority on technical and technological factor, the lowest priority is given to alternative A99, leader in environmental factors, but with the high cost of $\mathrm{CO}_{2}$ disposal technologies. The consistency ratio of local priorities at different stages of the calculation does not exceed 0.1 , the error in estimating the priorities of alternative projects is $3.34 \%$, which is acceptable.

\section{Modernization of the ash and slag removal system at a coal power plant}

The model was built on the basis of data on the activity of Novocherkasskaya TPP (NchGRES). The following restrictions have been adopted: the choice strategy is determined by the owner of NchGRES - United Generating Company-2; he is also an investor who, while minimizing costs, wants to get the maximum profit; an increase in the area of ash and slag dumps is not allowed. Alternative projects: WP - without processing; MS crushing and the simplest pneumatic mechanical separation of the mixture AHM; CMI - the release of carbon underburning and magnetic separation of the iron- containing ash fraction, as well as crushing and mechanical separation of slag; ES - retrofit of boiler plants with liquid slag removal devices for the electrolysis of molten slag; CS - full complex separation of ash and slag according to modern technologies. Factors (groups of criteria) and criteria: economic (EN): necessary investments (IN), project payback period (PPP), project duration (PD), project profitability (PP), competitiveness, demand for products in the market in the region and beyond (CD); ecological (EL): reducing the area of ash and slag dumps (RD), reducing harmful emissions into the atmosphere (REA), reducing pollution of the water basin (RW), reducing environmental charges (REP); technical and technological (TT): the availability of mass-produced (or custom-made) manufactured equipment (AE), the availability of ready-made design and technological solutions (DT), adaptability of equipment and technologies to specific operating conditions (AC), technical complexity (simplicity) installation, maintenance and repair of the installation, availability of guarantees of suppliers (SM), complexity (simplicity) of operation of the installation (SO); social $(\mathrm{S})$ : the creation of new jobs $(\mathrm{NJ})$, the need for qualified personnel for project implementation (QP), the availability of training opportunities in the region (TO); others (additional and specific) factors $(\mathrm{O})$ : the possibility of implementing the project in the climatic conditions of the region (taking into account seasonal temperatures, water requirements, terrain, etc.) (PCR), impact of the effects of the project on the climatic conditions of the region (ECR), the need for project products and the possibility of its implementation directly in the region (NPR), the complexity of the delivery of equipment and components, installation and maintenance, taking into account the state of infrastructure, roads (IFR), the complexity of product sales in the region, in Russia, for export, taking into account the infrastructure of the region (PS). The incomplete multifactor model of the problem is presented in Fig. 3, the results of the calculations - in the table 4.

The final comprehensive assessment of the alternative projects priorities (Table 4) shows that, from the owner's point of view, it is advantageous to organize the removal of ash and slag materials from the TPP territory with the smallest investment by selling raw ash-and-slag materials at the lowest price for further use and processing (WP project). 


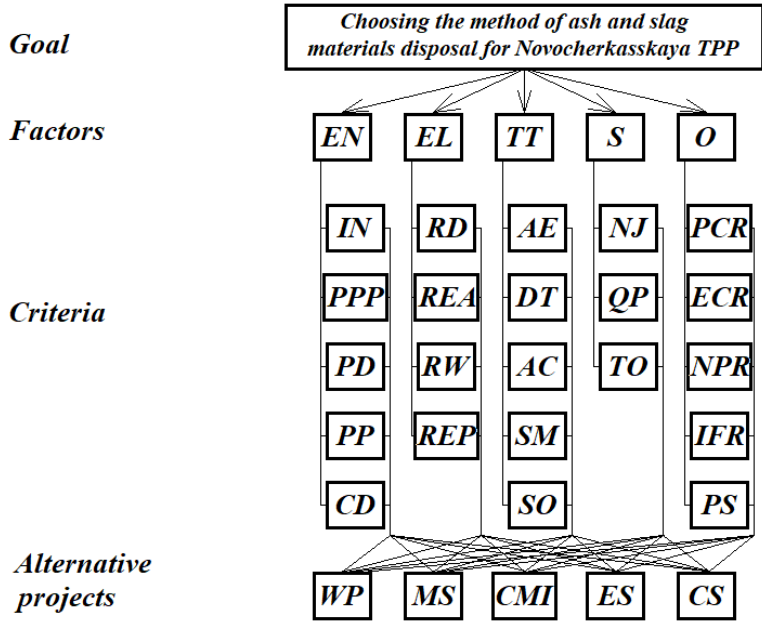

Fig. 3. Model of the problem of choosing the method of ash and slag materials disposal for NchGRES.

Table 4. Evaluation of global priorities for alternative projects, UASM.

\begin{tabular}{|c|c|c|c|c|c|c|}
\hline \multirow{3}{*}{$\begin{array}{c}\text { Alternative } \\
\text { projects }\end{array}$} & \multicolumn{5}{|c|}{ Factors and priorities } & \multirow{3}{*}{$\begin{array}{l}\text { Final } \\
\text { grade }\end{array}$} \\
\hline & EN & EL & TT & $\mathrm{S}$ & $\mathrm{O}$ & \\
\hline & 0.43 & 0.10 & 0.28 & 0.03 & 0.16 & \\
\hline WP & 0.28 & 0.20 & 0.41 & 0.18 & 0.23 & 0.30 \\
\hline MS & 0.22 & 0.07 & 0.27 & 0.18 & 0.29 & 0.23 \\
\hline CMI & 0.18 & 0.15 & 0.18 & 0.17 & 0.16 & 0.17 \\
\hline ES & 0.13 & 0.26 & 0.04 & 0.20 & 0.13 & 0.12 \\
\hline CS & 0.19 & 0.32 & 0.10 & 0.27 & 0.19 & 0.18 \\
\hline $\begin{array}{c}\text { Amount } \\
\text { by column }\end{array}$ & 1 & 1 & 1 & 1 & 1 & 1 \\
\hline
\end{tabular}

In order to reduce the subjectivity in assessing the global priorities of alternative projects, it is proposed to investigate the change in the numerical values of the global priorities of alternatives in the entire acceptable range of top-level priorities:

$$
p_{1}+p_{2}+p_{3}+p_{4}+p_{5}=1,0 \leq p_{\mathrm{i}} \leq 1, \mathrm{i}=1 \ldots 5,
$$

where $p_{i}$ is the priority of the $\mathrm{i}$-factor.

The global priorities of alternative projects $\mathrm{xi}$ in this case are determined by a system of equations (equalities), according to the table 4 :

$$
\left\{\begin{array}{l}
x_{1}=0,29 p_{1}+0,20 p_{2}+0,41 p_{3}+0,18 p_{4}+0,23 p_{5} \\
x_{2}=0,22 p_{1}+0,07 p_{2}+0,27 p_{3}+0,18 p_{4}+0,29 p_{5} \\
x_{3}=0,18 p_{1}+0,15 p_{2}+0,18 p_{3}+0,17 p_{4}+0,16 p_{5} \\
x_{4}=0,13 p_{1}+0,26 p_{2}+0,03 p_{3}+0,20 p_{4}+0,13 p_{5} \\
x_{5}=0,19 p_{1}+0,32 p_{2}+0,10 p_{3}+0,28 p_{4}+0,19 p_{5}
\end{array}\right.
$$

As a result, we obtain the linear optimization problem: for a system of linear equations and inequalities 1, 2, determine the values (intervals of values) of the priorities of the pi factors for which the global priority of the i-th alternative project xi is greater than the global priorities of the other projects. Solving this problem with the use of the Maple program showed that for alternative projects 1 (WP), 2 (MS) and 5 (CS) there are such combinations of priorities of factors under which these projects gain global priority that exceeds the global priorities of the others (four) projects. On the other hand, alternative projects 3
(CMI) and 4 (ES), under no combination of priorities of factors (or subjective preferences of the decision maker) objectively can not get the maximum global priority. This does not mean that projects 3 and 4 should be completely abandoned. But at this stage of technical development, their industrial realization is inexpedient.

\section{Modernization of the gas cleaning system at thermal power plants}

We accept restrictions: the choice strategy is determined by the owner of the TPP or the modernization investor, for which the priority is minimizing financial investments and risks while maximizing profits and the competitiveness of products; it operates within the framework of the legal field of the Russian Federation; finances only production and does not seek to invest his money in the development of science, therefore he chooses known technologies and serially produced equipment; the owner / investor has his own political interests in the region where the TPP is located, and therefore strives to create a favorable social background by creating new jobs. Alternative projects: TC (1) («zero option») - the use of traditional gas cleaning methods, the disposal of cleaning products is absent, the flue gas temperature is above the dew point; TC + FGC (2) - introduction of flue gas cooling technology below the dew point using serial equipment, separation of cooled gases and burial / storage of liquid separation products; TC + FGC + LSP (3) - introduction of flue gas cooling technology below the dew point, separation of cooled gases and production of new commercial products based on liquid separation products; TC + FGC + LSP + CO2 (4) - introduction of flue gas cooling technology below the dew point, separation of cooled gases and production of new commercial products based on liquid separation products, separation and processing of carbon dioxide. Factors (groups of criteria) and criteria: economic (EN): necessary investments (IN), project payback period (PPP), project duration (PD), project profitability (PP), competitiveness, demand for products in the market in the region and beyond (CD); legal (LE): the absence of a legal conflict with modern legislation of the Russian Federation (ALC), the presence of legislative support for investment initiatives in the Russian Federation (PLS), the compliance of the project with international legislation (IL); technical and technological (TT): the availability of mass-produced (or custom-made) manufactured equipment (AE), the availability of ready-made design and technological solutions (DT), the complexity (simplicity) of installation and operation of the equipment (SOE); ecological (EL): reduction of harmful emissions into the atmosphere (REA), elimination of «acid rain» (AR), reduction of the greenhouse effect (GE), reduction of environmental charges (REC); social (S): the creation of new jobs (NJ), the need for qualified personnel for project implementation (QP); the availability of training opportunities in the region (TO); risk (R): investment (IR), legal (LR), technical-technological (TR), ecological (ER), social (SR) and other (OR) risks associated with the implementation of the project. 


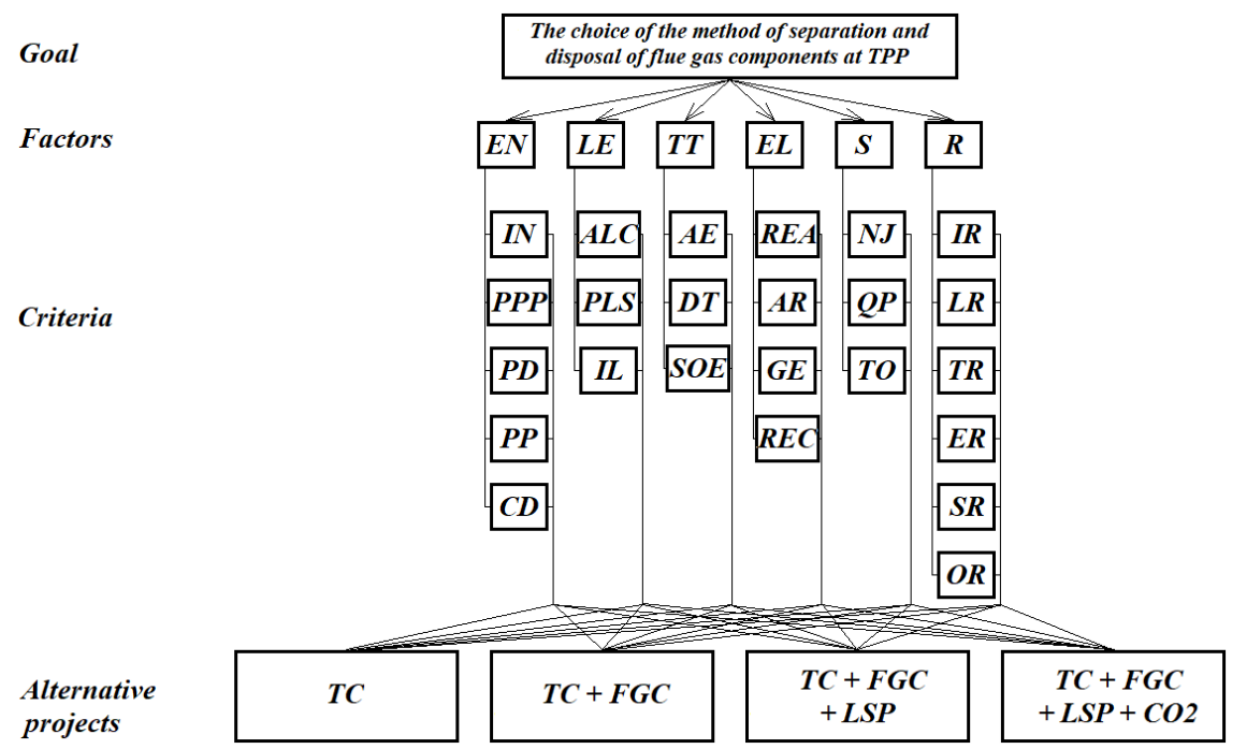

Fig. 4. Model of the problem of choosing a modernization strategy for the flue gas cleaning system at TPP.

The incomplete multifactor model of the problem is presented in Fig. 4. The results of the calculations are presented in table 5-6.

Table 5. Final matrix for assessing global priorities of alternative projects with low significance of ecological criteria, GCS.

\begin{tabular}{|c|c|c|c|c|c|c|c|}
\hline \multirow{3}{*}{$\begin{array}{c}\text { Alternative } \\
\text { projects }\end{array}$} & \multicolumn{6}{|c|}{ Factors and priorities } & \multirow{3}{*}{$\begin{array}{l}\text { Final } \\
\text { grade }\end{array}$} \\
\hline & EN & LE & TT & EL & $\mathrm{S}$ & $\mathrm{R}$ & \\
\hline & 0.34 & 0.25 & 0.18 & 0.04 & 0.12 & 0.07 & \\
\hline $\mathrm{TC}$ & 0.29 & 0.31 & 0.42 & 0.08 & 0.11 & 0.37 & 0.30 \\
\hline $\mathrm{TC}+\mathrm{FGC}$ & 0.24 & 0.30 & 0.31 & 0.21 & 0.16 & 0.31 & 0.26 \\
\hline $\begin{array}{c}\mathrm{TC}+\mathrm{FGC}+ \\
\mathrm{LSP} \\
\end{array}$ & 0.28 & 0.29 & 0.23 & 0.21 & 0.27 & 0.28 & 0.27 \\
\hline $\begin{array}{l}\mathrm{TC}+\mathrm{FGC}+ \\
\mathrm{LSP}+\mathrm{CO} 2\end{array}$ & 0.19 & 0.10 & 0.04 & 0.50 & 0.46 & 0.04 & 0.17 \\
\hline $\begin{array}{l}\text { Amount by } \\
\text { column }\end{array}$ & 1 & 1 & 1 & 1 & 1 & 1 & 1 \\
\hline
\end{tabular}

Table 6. Final matrix for assessing global priorities of alternative projects with low significance of ecological criteria, GCS.

\begin{tabular}{|c|c|c|c|c|c|c|c|}
\hline \multirow{3}{*}{$\begin{array}{l}\text { Alternative } \\
\text { projects }\end{array}$} & \multicolumn{6}{|c|}{ Criteria groups and priorities } & \multirow{3}{*}{$\begin{array}{l}\text { Final } \\
\text { grade }\end{array}$} \\
\hline & EN & LE & TT & $\mathrm{EL}$ & $\mathrm{S}$ & $\mathrm{R}$ & \\
\hline & 0.34 & 0.25 & 0.07 & 0.18 & 0.12 & 0.04 & \\
\hline $\mathrm{TC}$ & 0.29 & 0.31 & 0.42 & 0.08 & 0.11 & 0.37 & 0.25 \\
\hline $\mathrm{TC}+\mathrm{FGC}$ & 0.24 & 0.30 & 0.31 & 0.21 & 0.16 & 0.31 & 0.25 \\
\hline $\begin{array}{c}\mathrm{TC}+\mathrm{FGC}+ \\
\mathrm{LSP}\end{array}$ & 0.28 & 0.29 & 0.23 & 0.21 & 0.27 & 0.28 & 0.26 \\
\hline $\begin{array}{l}\mathrm{TC}+\mathrm{FGC}+ \\
\mathrm{LSP}+\mathrm{CO} 2\end{array}$ & 0.19 & 0.10 & 0.04 & 0.50 & 0.46 & 0.04 & 0.24 \\
\hline $\begin{array}{l}\text { Amount by } \\
\text { column }\end{array}$ & 1 & 1 & 1 & 1 & 1 & 1 & 1 \\
\hline
\end{tabular}

According to the table 5-6, on the factors EN, LE, TT and $\mathrm{R}$ is the highest priority in traditional cleaning, as in the cheapest, provided with equipment and technologies that comply with the legislation of the Russian Federation associated with the lowest level of various risks.

Technologies associated with cooling of flue gases below the dew point are not far behind the importance of traditional cleaning. According to the factors EL and C, the technology involving the utilization of carbon dioxide is leads.

If for investors the priority of ecological criteria is minimal (table 5), then alternative 1 has the highest global priority, and alternative 4, the leader in terms of ecological and social criteria, is generally the least priority. If the ecological criteria for significance for an investor moves to 3 rd place (table 6), then project 3 becomes the highest priority in terms of indicators, providing for cooling of flue gases below the dew point and production of liquid acid products based on flue gas components.

\section{Modernization of coal-fired thermal power plant in the energetic technological complex}

The choice of the modernization strategy for TPP in the ETC is based on the results presented above in this paper, on the example of Novocherkasskaya GRES. The accepted restrictions coincide with those adopted earlier: the choice strategy is determined by the owner of the TPP or the modernization investor, which operates within the legal framework, finances only production, therefore chooses primarily known technologies and serially manufactured equipment, seeks to maximize profits, minimize environmental damage and various risks, and supports the creation of a favorable social background in the region where TPP is located. The goal of modernization is the choice of a strategy for complex modernization of NchGRES, which allows the implementation of the functions and the solution of the most acute problems of the TPP operation. The goal of modernization is the choice of a strategy for complex modernization of NchGRES, 
which allows the implementation of the functions and the solution of the most acute problems of the TPP operation.

Functions of the modernized TPP. For traditional TPP, one function is defined - the production of electrical and thermal energy. The energetic technological complex on the basis of thermal power plant has two functions energy production (FEP) and production of commodity products from the waste of energy production (FCP).

Problems for which the modernization is carried out: the accumulation of ash and slag dumps (ASD); the need to burn coal of low (degraded) quality (PQC); moral and physical deterioration of equipment (TWE).

To assess the effectiveness of modernization projects, a «zero option» is introduced - a project that does not include the introduction of new technologies, but only the replacement of obsolete equipment with new, conservation of traditional technologies. Projects that are different from the «zero option», we call innovative.

Tasks of innovative projects: utilization of ash and slag materials - necessarily; in non-modernized process lines, replacement of outdated equipment with new, i.e. any innovative project by default includes the «zero option»necessarily; modernization of one or several technological lines, taking into account the modern level of development of engineering and technology, - is possible.

Alternative projects are generated based on the above results, as a direction of modernization of individual technological lines, the most priority projects in the corresponding direction, different from the «zero option», were taken. Projects are evaluated: 1) TT - traditional technology («zero option»), replacing outdated equipment with a new one without changing the technology of energy production and without introducing technologies for utilization of side products of energy production; 2) ASM - preparation of ASM for utilization by crushing and the simplest pneumatic mechanical separation; 3) ASM + CE - preparation of CE for disposal under item 2, enrichment of coal before burning and preparation of coal waste for disposal, similarly to item 2; 4) ASM + AE - preparation of ASM for disposal under item 2, air enrichment to $50 \%$ oxygen content before being fed to combustion; 5) ASM + COGA - preparation of ASM for disposal under item 2, cooling of the flue gases below the dew point and the production of acidic marketable products; 6) ASM + CE + $\mathrm{AE}$ - preparation of ASM for disposal under item 2, coal enrichment according to item 3, air enrichment according to item 4 ; 7) ASM + CE + COGA - preparation of ASM for utilization under item 2, coal enrichment under item 3, cooling of the flue gases under item 5 ; 8) ASM + AE + COGA - preparation of ash and slag material for disposal according to item 2, air enrichment of according to item 4 , cooling of flue gases according to item 5; 9) ASM + CE + $\mathrm{AE}+\mathrm{COGA}$ - full option, preparation of ASM for disposal under item 2, coal enrichment according to item 3 , air enrichment according to item 4 , cooling of flue gases according to item 5 .

Groups of criteria (factors) and criteria are similar to those presented above. The criteria for the liquidation of ash and slag dumps (LD) has been added to ecological criteria. Each of the criteria affects each of the alternatives. Priorities of alternatives for each of the criteria, priorities of alternatives by a group of criteria (factors), priorities of alternatives by the level of problem solving, global priorities of alternatives, as well as global priorities of problems, priorities of factors by problems and global priorities of factors, priorities of criteria by factors, priorities of criteria by problems and global priorities of criteria. Several options of priorities factors (diversity) will be considered.

Studies have shown that the simple hierarchical Saaty model of does not adequately reflect the realities of production processes. In particular, given the priority of the economic factor for solving the problem of the liquidation of ash and slag dumps, the highest global priority turned out to be the most comprehensive and expensive alternative project and the alternative TT project («zero option»), which does not contain equipment for utilizing ash and slag, but implies only their accumulation, storage, at best - conservation of dumps. Alternatives are more clearly evaluated directly by their influence on the solution of both production tasks and problems. In general, since consideration of the impact of existing problems on the choice of modernization strategy is necessary, but the level of problems does not fit into the hierarchy, it was decided to allocate it into a separate branch - but not into a separate model. A modification of the Saaty method, the «parallel hierarchy process», is proposed. The essence of the method:

1) All aspects that are adequately incompatible with each other, from the point of view of which proposed alternatives can be considered, which at the same time must be taken into account when deciding on the choice of strategy, are highlighted in parallel branches.

2) The number of levels of criteria and the criteria themselves in each parallel can be different or overlap.

3) The priority and hierarchy of the parallels themselves are introduced.

4) Priorities of alternatives are calculated for each parallel.

5) Along with the convolution procedure for moving to a higher level in the hierarchy, a procedure for assembling priorities derived from different parallels is introduced.

6) The priorities within the parallels are sequentially collapsed (convolution) and the priorities are assembled over all the parallels taking into account the priorities of the parallels, and the global priorities of alternatives are calculated.

7) In more complex tasks, each of the parallels can be divided into several parallels (from 2 to 9 ) of the lower level.

The assembly procedure, after obtaining the priorities of the alternatives for each parallel, is that these row vectors are written sequentially in a matrix format:

$$
{ }^{j} G_{i-1, i}=\left(\begin{array}{c}
G_{i, j}^{k} \\
G_{i, j}^{k+1} \\
\cdots \\
G_{i, j}^{k+n-1}
\end{array}\right),
$$

where the assembly is made for $n$ parallels numbered from $\mathrm{k}$ to $\mathrm{k}+\mathrm{n}-1$, while initially objects of level $\mathrm{j}$ were evaluated from the standpoint of criteria of level $i, k \geq 1$, $\mathrm{n} \geq 1,2 \leq \mathrm{i}<\mathrm{j}$. As a result of the assembly, we rise in 
assessments from the i-th to the i-1-st level of the hierarchy (the goal level is the first level of the hierarchy, the level of alternatives is the maximum by number). In general, matrices with the same number of columns can be assembled.

A parallel hierarchical process of the problem of choosing a strategy for complex modernization of a coalfired thermal power plant on the example of the NchGRES is presented in fig. 5 ( $\mathrm{PD}$ - production parallel, $\mathrm{PB}-$ problem parallel), the graphical model is presented in fig. 6. The numbering of transition matrices in fig. 6: the upper right index is the number of the parallel; the right lower indices - the left of them denotes the upper level of comparison, the right one denotes the lower level of comparison, the aspects of the lower level are considered from the perspective of aspects of the upper level; the left upper index is the aspects of the lowest level that will be taken into account when assembling priorities along parallels. Designations in fig. 6: PR - parallels, PD production (main) parallel, AC -additional conditions parallel, $\mathrm{PB}$ - problems. The results of the calculations are presented in table 7. Designations in the table. 7: EQ equal significance $0.5 / 0.5, \mathrm{NEQ}$ - unequal significance 0.67 (PD, FEP) / 0.33 (PB, FCP).

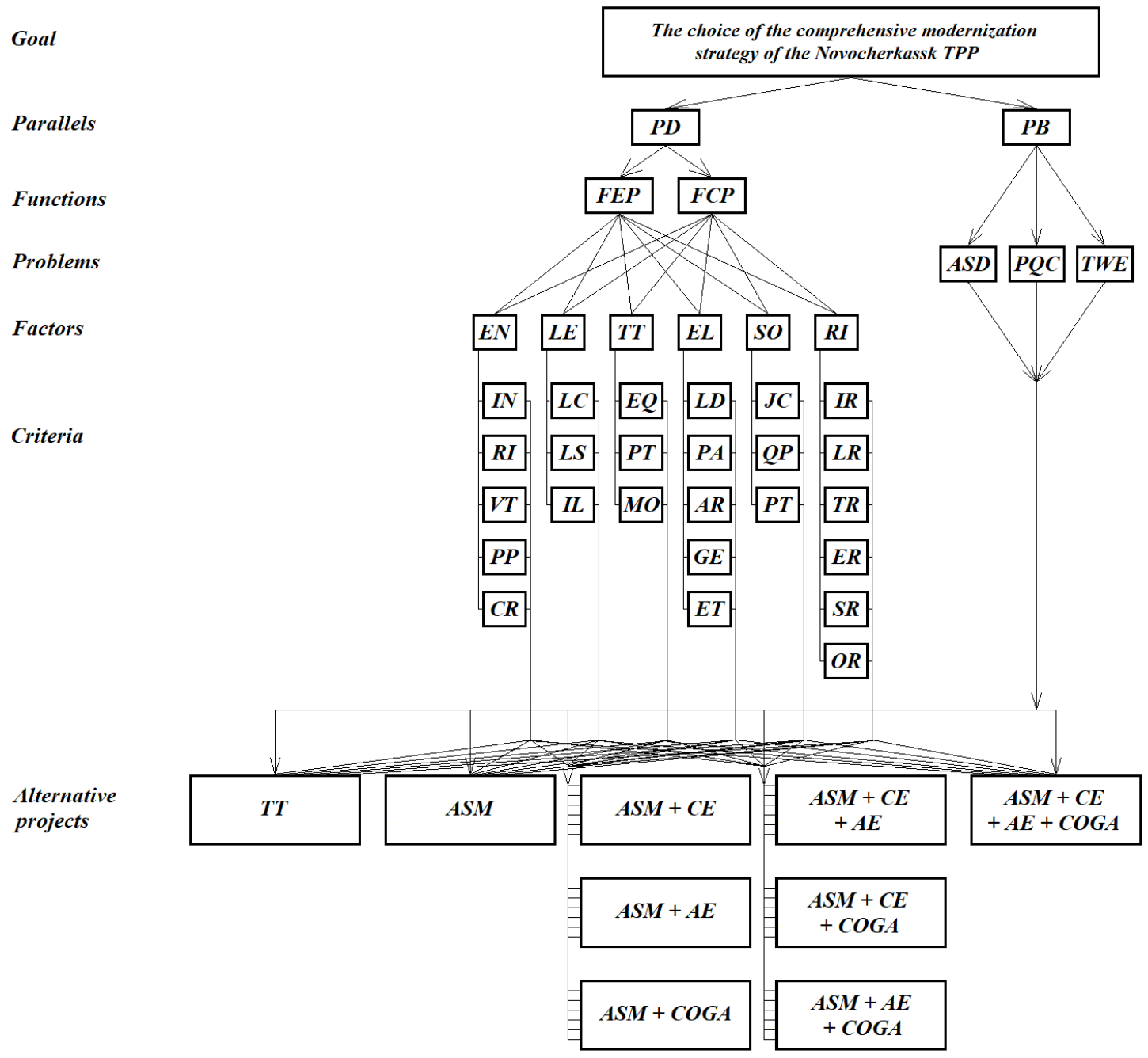

Fig. 5. Parallel hierarchical process of the problem of choosing a strategy for complex modernization of NchGRES.

Table 7. Final priorities of TPP modernization projects ${ }^{7} G_{13}$ with different ratios of the importance of parallels and production functions.

\begin{tabular}{|c|c|c|c|c|c|c|c|c|c|}
\hline \multirow{2}{*}{ Diversity } & \multicolumn{10}{|c|}{ Alternative projects } \\
\cline { 2 - 10 } & TT & ASM & $\begin{array}{c}\text { ASM+ } \\
\text { CE }\end{array}$ & $\begin{array}{c}\text { ASM+ } \\
\text { AE }\end{array}$ & $\begin{array}{c}\text { ASM+ } \\
\text { COGA }\end{array}$ & $\begin{array}{c}\text { ASM+CE } \\
+ \text { AE }\end{array}$ & $\begin{array}{c}\text { ASM+CE } \\
+ \text { COGA }\end{array}$ & $\begin{array}{c}\text { ASM+AE } \\
+ \text { COGA }\end{array}$ & $\begin{array}{c}\text { ASM+CE+ } \\
\text { AE+COGA }\end{array}$ \\
\hline $\begin{array}{c}\text { EQ of functions + EQ of } \\
\text { production and problems }\end{array}$ & 0,132 & 0,172 & 0,137 & 0,112 & 0,122 & 0,083 & 0,092 & 0,076 & 0,075 \\
\hline EQ + NEQ & 0,151 & 0,162 & 0,130 & 0,105 & 0,121 & 0,080 & 0,092 & 0,077 & 0,082 \\
\hline NEQ + EQ & 0,134 & 0,172 & 0,138 & 0,112 & 0,123 & 0,082 & 0,091 & 0,075 & 0,074 \\
\hline NEQ + NEQ & 0,153 & 0,162 & 0,131 & 0,105 & 0,122 & 0,079 & 0,090 & 0,076 & 0,081 \\
\hline
\end{tabular}




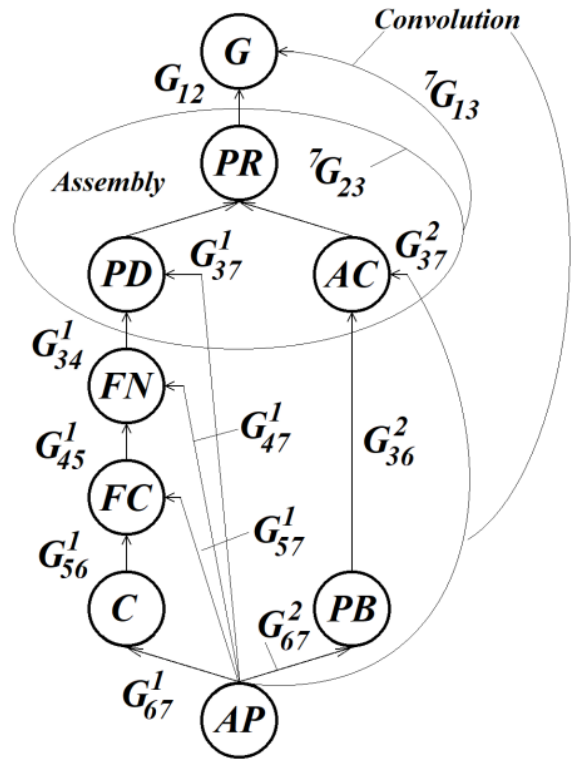

Fig. 6. Graphic model of the problem of choosing a strategy for complex modernization of NchGRES for a parallel hierarchy.

As can be seen from the table 7, stably on the first place on the priority is an alternative ASM, the second and third places are shared by traditional technology and modernization, providing separation ASM and enrichment of coal. Complex technologies have a much lower priority due to their high cost, technical complexity and lack of legal support.

Denote the global priority of the i-th alternative project as pi, the priority of the production parallel $\mathrm{p}$, then the priority of the problem parallel $(1-p)$. Taking into account the results of intermediate calculations, we obtain a set of linear equations and inequalities of the form:

$$
\begin{gathered}
\left\{\begin{array}{l}
p_{1}=p(0,190-0,075)+0,075 \\
p_{2}=p(0,142-0,201)+0,201 \\
p_{3}=p(0,117-0,157)+0,157 \\
p_{4}=p(0,091-0,132)+0,132 \\
p_{5}=p(0,119-0,126)+0,126 \\
p_{6}=p(0,075-0,091)+0,091 \\
p_{7}=p(0,092-0,091)+0,091 \\
p_{8}=p(0,079-0,073)+0,073 \\
p_{9}=p(0,096-0,054)+0,054
\end{array}\right. \\
\sum_{i=1}^{9} p_{\mathrm{i}}=1 . \\
0 \leq p \leq 1,0 \leq p_{\mathrm{i}} \leq 1, \mathrm{i}=\overline{1 \ldots 9} .
\end{gathered}
$$

The problem of linear optimization: for equations 4,5 and inequalities 6 , find the ranges of $p$, the values of $i$ and pi, for which

$$
p_{\mathrm{i}}>p_{\mathrm{j}} \forall \mathrm{i} \neq \mathrm{j}, \mathrm{i}, \mathrm{j}=\overline{1 \ldots 9} .
$$

Solving this problem by numerical methods shows that alternative projects $6-9$ are not among the top three for any values of $\mathrm{p}$.

For this model, you can set the problem of nonlinear optimization. Let us denote the priority of the production parallel $\mathrm{p}$, the priority of the problem parallel $(1-p)$, the priority of the FEP q, the priority of the FCP $(1-q)$. Linear equations 4 are converted to a non-linear form:

$$
\left\{\begin{array}{l}
p_{1}=p q(0,199-0,180)+p(0,180-0,075)+0,075 \\
p_{2}=p q(0,144-0,140)+p(0,140-0,201)+0,201 \\
p_{3}=p q(0,120-0,114)+p(0,114-0,157)+0,157 \\
p_{4}=p q(0,093-0,090)+p(0,090-0,132)+0,132 \\
p_{5}=p q(0,121-0,117)+p(0,117-0,126)+0,126 \\
p_{6}=p q(0,071-0,078)+p(0,078-0,091)+0,091 \\
p_{7}=p q(0,086-0,097)+p(0,097-0,091)+0,091 \\
p_{8}=p q(0,075-0,082)+p(0,082-0,073)+0,073 \\
p_{9}=p q(0,090-0,102)+p(0,102-0,054)+0,054
\end{array}\right.
$$

For the nonlinear optimization problem, the equality 5 will not change, the system of inequalities 6 will take the form:

$$
0 \leq p \leq 1,0 \leq q \leq 1,0 \leq p_{\mathrm{i}} \leq 1, \mathrm{i}=\overline{1 \ldots 9} .
$$

We obtain the problem of nonlinear optimization: for equations 8,5 and inequalities 9 , find the ranges of $\mathrm{p}, \mathrm{q}$, the values of $i$ and pi, for which

$$
p_{\mathrm{i}}>p_{\mathrm{j}} \forall \mathrm{i} \neq \mathrm{j}, \mathrm{i}, \mathrm{j}=\overline{1 \ldots 9} .
$$

The results of numerical calculations with a step of 0.1 to change the priorities of $\mathrm{p}$ and $\mathrm{q}$ showed that for priority $\mathrm{q}=0.5$, the highest (first) priority can be only for alternatives 2 (ASM) and 1 (TT), while the priority of alternative 1 increases with increasing priority of the production parallel. Alternative project 3 (ASM $+\mathrm{CE}$ ) may become second in priority with the increasing importance of the problem parallel and / or function of commodity production. Among the three most highpriority alternative projects, there are only projects with numbers from 1 to 5 , providing for radical modernization of no more than 2 subsystems of TPP. In this case, only 1 and 2 projects can have the highest priority (1), 1, 2 or 3 projects may be second in priority, 1, 3, 4 or 5 projects may be third in priority. Project 9 (simultaneous modernization of all subsystems of thermal power plant) at any ratio of $p$ and $\mathrm{q}$ is the least priority. Alternative 2 (ASM) can have only the highest or second global priority, and $73 \%$ of cases it has the first priority (of which in $5 \%$ of cases it is divided with alternative 1). Alternative 1 (TT) has a wide variation in possible priority, being the highest priority in $32 \%$ of cases. Thus, the highest global priority of alternative 2 is more resilient to changes in the priority of the top-level criteria. At certain ratios of the parameters $p$ and q, alternative $3(\mathrm{ASM}+\mathrm{CE}$ ) can take 2 nd place in the priority ranking, i.e. also quite promising for implementation. Alternatives 4 (ASM + AE) and 5 (ASM + COGA) may occupy the 3rd place in the ranking of priorities. Alternatives 6 (ASM $+\mathrm{CE}+\mathrm{AE})$ and 7 (ASM $+\mathrm{CE}+\mathrm{COGA}$ ) occupy maximum 4 place, alternative 8 $(\mathrm{ZSHM}+\mathrm{AE}+\mathrm{COGA})-$ maximum 5 , alternative 9 (ASM $+\mathrm{CE}+\mathrm{AE}+\mathrm{COGA})-$ maximum 6 (despite the fact that the remaining alternatives have a higher priority in this case), which proves the inexpediency of large-scale projects involving the fundamental modernization of more than two subsystems of TPP simultaneously. 


\section{The specifics of the application of the Saaty method to the choice of strategy for the modernization of energy (production) facilities}

On the whole, an analysis of the process and results of the choice of the modernization strategy for energy (production) facilities using the Saaty method showed the following.

1) The larger and more complex the proposed modernization, the more hierarchy levels the problem model contains. The most difficult of the models we reviewed contained 7 levels of hierarchy, where 1 (highest) level is the goal of modernization, 7 (lowest) level - alternative projects to achieve the goal, level 6 - the lowest level criteria for assessing the priority of alternatives (for example, using the method of pairwise comparisons). Simplified models do not allow to reflect all aspects of a complex system.

2) The choice of design goals is made by the decision maker.

3) The choice of alternative projects for analysis is carried out by experts.

4) The selection of criteria for evaluating alternative projects depends on the goal of the modernization. But in any case, it is recommended to consider at least three criteria (aspects): economic, technical, and others. In simple three-level models, the predominance of criteria of one aspect increases its priority and shifts the evaluation of alternatives.

5) To increase the visibility and structure of a complex model, criteria for assessing the priority of alternatives can be grouped. There is a set of eight groups of criteria (factors) on which the choice of strategy is based: economic, technical (and technological), ecological, legal, organizational, social, risk, and others. Others include all criteria that cannot be attributed to other groups, but must be taken into account in a specific model. This set of factors covers all aspects and stages of the life cycle of an energy (production) facility - design, construction, operation. The choice of groups and specific criteria from the group is justified both by the specifics of the task and the preferences of the expert or decision maker.

6) In the tasks of choosing a modernization strategy for energy (production) facility, the highest priority was given to economic criteria. Therefore, the most priority were the cheapest and simplest strategies. In particular, if a conservative, so-called «zero option» was introduced into consideration, that is, the replacement of old equipment with a new one without a change in technology, then this option invariably won, sometimes with a large margin. But this decision is not a modernization of production. Therefore, when choosing a modernization project in such situations, it is recommended to pay attention to the second priority option and evaluate the difference in the global priorities of the «zero option» and the second priority project. It should be noted that when using AHP in other areas (not in evaluating production modernization projects), a project similar to the «zero option» may be absent. But when solving production problems, a comparison with «zero options» gives an idea of the innovative project effectiveness.

7) Combining criteria into groups (factors), when the influence of a group extends only within the group, but not to the criteria of other groups, allows us to introduce parallel hierarchies and, in particular, visually consider the influence of different specifics factors or point of view of each independent expert.

8) The need to take into account in one hierarchical model of higher levels factors (actors), for which it is impossible to evaluate their mutual dependence, subordination, can lead to absurd results. These are actors of one influence level. The parallel hierarchies process allows considering non-subordinate actors (for example, tasks and problems of enterprise functioning), including a different number of internal hierarchical levels.

9) In parallel hierarchical models, along with the convolution procedure widely described in the literature on the Saaty method, implemented as a matrix multiplication and allowing to evaluate the lower level criteria from the position of the highest non-adjacent level, introduces the procedure for assembling priority vectors obtained along parallel branches of the hierarchy into an evaluation matrix of a higher level corresponding to the division of the hierarchy into parallels.

10) Parallel hierarchical models are reducible to classical Saaty hierarchies by introducing fictitious hierarchy levels and sparse transition matrices from the lowest to the highest hierarchy level.

11) The lowest level criteria (LLC) are specific and, as a rule, allow numerical expression (project cost, payback period, number of offers on the special equipment market, quantitative content of the recoverable component in ASM, amount of environmental payments, number of jobs created and $t$.) or at least a comparison of more / less (presence / absence of relevant laws, organizational structures). Therefore, the priorities of alternative projects regarding the LLC are obvious and do not cause any discussions.

12) The higher the level of the criterion, the less obvious the prioritization. Here the position of an expert or decision maker begins to play a big role. This may cast doubt on the proven global priority of the alternative project, and in some cases radically change the alignment of the global priorities of the alternatives. To analyze this situation, we introduce the concept of a diversity of prioritizing highlevel criteria. Consideration of several diversity direction for prioritizing the criteria of higher levels (functions, parallels) allows determining the sustainability of global priorities of alternatives to changing diversity direction and thereby increasing the validity of the assessment of global priorities of alternatives.

13) To reduce the influence of the decision makers subjectivity in assessing high-level priorities, it is also recommended to consider all alternative projects in an acceptable level of priority for low-level areas by reducing the task of evaluating global priorities of alternatives to the linear optimization task (one at a time, the highest hierarchy level) or non-linear optimization task (more than one level of hierarchy). 
14) Alternative projects that have not gained a high global priority in the modeling process should not be completely rejected. Perhaps, after a while, if the realities change (technology development, the emergence of specialized organizations, changes in legislation), these projects will turn out to be more attractive.

\section{Conclusion}

The analytical hierarchical process can be successfully applied in solving the problems of choosing a modernization strategy for energy (production) facilities. But it is necessary to take into account the specifics of these tasks when selecting and grouping evaluation criteria, building parallel hierarchies, when assessing the priority of "zero option" and taking measures to reduce the influence of the decision maker's subjectivity on the final project evaluations.

\section{References}

1. T.L. Saaty, Decision Sciences, 18, 157 (1987)

2. T. Saaty, Making Decisions. Analytic Hierarchy Process (Radio and Communication, Moscow, 1993)

3. A.A. Pyankov, XII All-Russian Meeting on the problems of the management of the All-Union Service Alert-2014 (Moscow, 2014)

4. A.I. Chernoskutov, E.F. Zorin, B.S. Ryzhov, Dual technologies, 2(51), 48 (2010)

5. K.S. Zhizhin, N.V. Blagorodova, StroyMnogo, 2(3) (2016)

URL:

http://stroymnogo.com/science/economy/ispolzovaniemetoda-analiza-ierarkh/

6. A.V. Prokopov, S.S. Shcherbak, Problems of Emergencies. Collection of scientific papers of the National University of Civil Protection of Ukraine. 12, 122 (2010)

7. A.V. Andreichikov, O.N. Andreichikova, Analysis, synthesis, planning decisions in the economy (Finance and Statistics, Moscow, 2000)

8. O.A. Akhmetov, M.B. Mzhelsky, Actual issues of valuation (Novosibirsk, 2001) URL: http://www.ocenchik.ru/docse/2129-metod-analizaierarhiy-mai-ocenki-nedvizhimosti.html 9. V.V. Platonov, I.A. Zubkov, Yu.A. Polushkovsky and others, Application of mathematical statistics methods to the analysis of precursors of earthquakes, possible for observation from space URL: d33.infospace.ru/d33_conf/vol2/141-146.pdf

10. S.I. Zolotukhin, M.Yu. Sinev, A.O. Shmoylov, Fundamental research, 12-2, 284 (Moscow, 2016)

11. N.V. Fedorova, N.N. Efimov, Y.V. Fedorov, Safety and Reliability of Power Industry, 11(1), 54 (Moscow, 2018)

12. N.V. Fedorova, V.A. Mokhov, E.A. Krivobok, Biosciences Biotechnology Research Asia, 12(3) (2015) URL: http://www.biotech-asia.org/vol12no3/functionalsimulation-of-the-method-for-the-coal-preparation-forcombustion-in-the-thermal-power-plant/ 